\title{
Regulation in the face of uncertainty: the evidence on electronic nicotine delivery systems (e-cigarettes)
}

This article was published in the following Dove Press journal:

Risk Management and Healthcare Policy

29 September 2015

Number of times this article has been viewed

\author{
Konstantinos E Farsalinos ${ }^{1,2}$ \\ Jacques Le Houezec ${ }^{3,4}$ \\ 'Department of Cardiology, Onassis \\ Cardiac Surgery Center, Kallithea, \\ ${ }^{2}$ Department of Pharmacy, University \\ of Patras, Patras, Greece; ${ }^{3}$ Division \\ of Epidemiology and Public Health, \\ UK Centre for Tobacco and Alcohol \\ Studies, University of Nottingham, \\ Nottingham, England, UK; ${ }^{4}$ Addiction \\ Research Unit, INSERM I I 78 (Mental \\ and Public Health), Paris, France
}

\begin{abstract}
Tobacco smoking is the largest single preventable cause of many chronic diseases and death. Effective treatments exist; however, few smokers use them and most try to quit by themselves. Most of the tobacco cigarette's toxicity is related to the combustion process. Models of harm reduction applied to tobacco suggest that switching from inhalation of combustible products to a noncombustible nicotine delivery product would likely result in a vast reduction in tobacco-related death and illness. Currently available evidence raises no doubt that electronic cigarettes (e-cigs) are by far less harmful than smoking (although probably not absolutely safe) and have the potential to be the most effective tobacco harm reduction products due to their unique property of resembling smoking and providing satisfaction to the user. A lot of controversy is surrounding e-cigs and their regulation, much of which is based on the precautionary principle. Although monitoring and further research is definitely needed, the arguments used to implement severe restrictions or bans are mostly hypothetical, weakly supported by evidence, and, in some cases, derived from mispresentation or misinterpretation of the study findings. Regulators should keep in mind that the target population is smokers who want to reduce or quit their deadly tobacco consumption. To achieve this goal, smokers should be honestly informed on the relative harmfulness of the different products. E-cigs are not tobacco products and are not used as medications. For this reason, a specific regulatory scheme is needed, separate from tobacco or medicinal products regulation. Regulation should implement specific quality criteria for products, rules for the exclusion of chemicals of reasonable concern, and appropriate testing for possible contaminants. Additionally, manufacturing standards derived from the food industry should be implemented and adjusted for specific conditions related to e-cigs. Finding the appropriate balance between safety and acceptability of use by smokers will be important in achieving the maximum public health benefit. Labeling should be specified, with warnings about exposure to skin or through ingestion and discouragement of use by nonsmokers, related to the presence of nicotine. Finally, advertising and marketing should not be banned, but appropriately regulated in order to encourage use by the intended population while avoiding use by never-smokers. E-cigs should be appealing to smokers (but not to nonsmokers), while availability and pricing should be strong competitive advantages of e-cigs relative to tobacco cigarettes.
\end{abstract}

Keywords: electronic cigarettes, nicotine, smoking, tobacco harm reduction, precautionary principle, regulation

\section{Introduction}

Tobacco smoking is classified as a chronic relapsing mental disorder. ${ }^{1,2}$ Most users struggle to achieve long-term abstinence, and often relapse. Although the potential role of substances found in tobacco or its smoke other than nicotine has not been ruled out (eg, monoamine oxidase $\mathrm{A}$ and $\mathrm{B}$ inhibitors), ${ }^{3,4}$ nicotine is considered to be the main addictive
Correspondence: Konstantinos E Farsalinos Department of Cardiology,

Onassis Cardiac Surgery Center, Sygrou 356, 17674 Kallithea, Greece

Tel +30697745 4837

Fax +302109493373

Email kfarsalinos@gmail.com 
ingredient in tobacco that causes and sustains tobacco dependence. ${ }^{5}$ Tobacco smoking is the largest single preventable cause of many chronic diseases, including cancers, pulmonary, and cardiovascular diseases, and currently causes more than 5 million deaths worldwide each year. ${ }^{6}$ It is predicted that smoking will be responsible for approximately 1 billion tobacco-related deaths during the 21 st century. ${ }^{7}$ Quitting early in life (before the age of 35 years) reduces by more than $90 \%$ the overall risk of morbidity and mortality both in men and women, but quitting at any age is beneficial. ${ }^{8,9}$ Effective treatments (including behavioral counseling, nicotine replacement therapy [NRT], bupropion, and varenicline) exist and are effective across a broad range of populations. But in practice, most smokers try to quit by themselves, which is the least effective method, and every year approximately $40 \%$ do quit for at least 1 day, but approximately $80 \%$ of smokers who attempt to quit on their own return to smoking within 1 month, and only $3 \%$ of smokers successfully quit each year. ${ }^{5}$ It is therefore important that efforts are made to reduce the harmfulness for those who cannot, or do not want to, stop.

\section{Tobacco harm reduction}

Cigarettes are the most deadly smoked tobacco product, because most toxicity is related to the burning process, and the health hazards of cigarette smoking are well known. ${ }^{8}$ Smoke is harmful (the combustion of any plant produces toxic substances such as carcinogens, carbon monoxide, oxidant gases, and solid fine particles), and smoking is the most addictive route of administration for a drug (eg, crack vs cocaine) because it rapidly delivers high doses of the drug to the brain. ${ }^{10,11}$ Nicotine is not completely harmless, but it is not responsible for most of the diseases due to tobacco use. Unfortunately, over the years, nicotine has been associated with tobacco-related diseases in many media campaigns against smoking. Because of this, there are strong barriers to the use of nicotine for the treatment of tobacco dependence, coming not only from tobacco users, but also from the medical community. ${ }^{12,13}$

Tobacco harm reduction is a strategy of reducing the net damage to health associated with the use of combustible tobacco products. Models of harm reduction applied to tobacco suggest that the use of noncombustible, less toxic, nicotine-containing products would be better than cigarette smoking and would limit tobacco-related deaths and disabilities. The sooner the action starts and the less hazardous the product is, the greater the harm reduction. ${ }^{14}$ Switching smokers from inhalation of combustible products to a noncombustible nicotine-delivery product would likely result in a vast reduction in tobacco-caused death and illness, via major reductions in lung cancer and chronic respiratory disorders. ${ }^{15}$ Until recently, two product categories were available for tobacco harm reduction: smokeless tobacco and NRT products. Smokeless tobacco products are not a homogeneous category, and the risk profile varies according to the products, but data from Sweden, where a large percentage of men use snus (a snuff product with reduced amount of nitrosamines) and the prevalence of smoking is lower than in other European country, show markedly lower rates of lung cancer compared with populations in other countries. Moreover, observational studies have also found that snus is used by many smokers to quit smoking. ${ }^{16}$ However, supplying snus is currently illegal in European Union (EU) countries other than Sweden. NRTs are generally regarded as safe even for long-term use, especially when compared to smoking. ${ }^{17,18}$ This has been recognized by medical authorities which propose the long-term use of NRTs as smoking substitutes. ${ }^{19,20}$ However, currently available NRT products have achieved only partial success with regard to these issues, because they provide nicotine at doses and rates of delivery that are a poor substitute for cigarettes. Despite that, it is reasonable to support that the ideal option, aside from quitting all nicotine use, would be for smokers to switch from cigarettes to a "clean nicotine delivery system", even if that might maintain the dependence on nicotine. ${ }^{21}$

\section{Electronic cigarettes}

A new nicotine delivery device is now gaining increasing support from smokers: electronic cigarettes (e-cigs) or personal vaporizers. These are devices consisting of the battery part (usually lithium battery, disposable or rechargeable) and an "atomizer", where liquid is stored and is aerosolized by applying energy and generating heat to a resistance coil encircling a wick. The liquid used mainly consists of propylene glycol, glycerol, water, flavorings (that may or may not be approved for food use), and nicotine. They were invented in 2003 by Hon Lik, a Chinese pharmacist, and, over the past years, awareness and use have grown exponentially. ${ }^{22-25}$ Initially, e-cigs were small devices resembling tobacco cigarettes in size and shape. Although these devices are still available on the market, more advanced devices have been developed in the past few years, with batteries of larger capacity and with integrated electronics that provide consumers the ability to adjust the functional characteristics and performance. Newer generation atomizers are refillable and have a transparent "window", allowing consumers to visually determine when they need to be refilled. As a result 
of rapid innovation, there is a large variability of e-cig products, with different combinations of atomizers and battery devices and a substantial number of e-cig liquids with different nicotine content and flavors. ${ }^{26,27}$ Besides variability, significant improvements in design characteristics, material choices (Pyrex glass instead of plastics, stainless steel instead of other metal alloys), and electronics (temperature control systems) have led to further improvements in terms of performance and safety.

E-cigs have the potential to be the most effective tobacco harm reduction product due to their unique property of resembling smoking in a way that no other product did until now. The visible aerosol (resembling smoke) that is exhaled and the motor and sensory stimulations could effectively address the psychobehavioral aspect of smoking dependence. ${ }^{28}$ This has been observed in preliminary studies using first-generation devices, which showed that although almost no nicotine was absorbed, smokers were able to suppress their nicotine craving by using these e-cigs. ${ }^{29,30}$ Newer generation products have been shown to be effective in delivering nicotine, ${ }^{31,32}$ therefore, e-cigs can also satisfy the pharmacological part of smoking dependence.

\section{Controversy over e-cigs}

There has been a strong debate and a lot of controversy surrounding e-cigs. There are strong supporters of e-cigs, thinking that they help in reduction or cessation of smoking, and equally strong opponents, thinking that they promote an addictive habit and endanger the long-term strategy of denormalizing smoking. ${ }^{33}$ Interestingly, it seems that the same e-cig characteristics and properties are perceived differently by the two sides: resemblance in experience to smoking and ability to deliver nicotine are perceived both as major advantages (for supporters) and dangers (for opponents) of e-cigs. The debate is not only between scientists, politicians, and regulators; e-cig users (vapers) have also been actively involved, both by publishing letters ${ }^{34}$ and in social media. ${ }^{35}$ Vapers feel ignored or insulted, ${ }^{34}$ but so do scientists. ${ }^{36}$ This is probably derived from the explosive growth in e-cig awareness and use over the last few years, indicating that e-cigs are indeed a disruptive technology. This is creating fears and a precautionary approach, which in many cases could be described as misleading, originating from ideological opposition. ${ }^{37,38}$ Characteristically, the reviews on e-cigarettes safety, analyzing almost the same studies, resulted in substantially different conclusions. ${ }^{39-41}$ This controversy, and the numerous media stories accompanying it, can only result in confusion not only among consumers, but also among politicians and regulators who have the responsibility to make decisions that affect public health and consumer protection.

\section{Current approach to e-cig regulation and the precautionary principle}

As an expected result of the aforementioned controversy, there are different approaches to e-cig regulation between different countries, and even between different states in the USA. ${ }^{42,43}$ In many countries, e-cigs are currently considered as a consumer product and are available on the Internet, in convenient stores, or in specialized shops. Several countries in South America and in Asia have introduced a complete ban on these products. In other cases, the regulation is related to the presence or absence of nicotine in the liquid. In the USA, the Food and Drug Administration (FDA) is working on a proposal to regulate e-cigs, while the EU decided to regulate e-cigs within the 2014 Tobacco Products Directive, which will be implemented in May 2016. Many regulators tend to classify them as tobacco products, mainly because this would facilitate tough regulations which already exist for tobacco products. The basis for this classification is that nicotine is derived from tobacco. However, it is hard to substantiate the appropriateness of such a legislation since there is no tobacco in e-cigs and nicotine is introduced in purified form according to pharmaceutical standards. Moreover, it is disproportionate to assimilate e-cigs with tobacco cigarettes, considering the vast difference in the risk profile of the two products.

Currently available evidence raises no doubt that e-cigs are by far less harmful than smoking. This can be supported by the facts that liquids are made from pharmaceutical grade basic ingredients (mainly propylene glycol, glycerol, and nicotine) and food-approved flavors, and there is no tobacco and no combustion involved in the aerosol production. Chemical, toxicological, and few clinical studies ${ }^{39-41}$ as well as surveys of users further support it. ${ }^{27,44}$ Of course, there are many areas that need further research, such as establishing the safety profile of food-approved flavors when inhaled and finding ways to further reduce the low levels of contaminants and thermal degradation products found in some studies. ${ }^{66-69}$ Two important facts need to be mentioned: 1) most likely, e-cigs are not absolutely harmless, although no studies have verified any significant adverse health effects till now; therefore, there is no reason for never-smokers to be exposed to any (even minimal) risk by initiating e-cig use and 2) it is currently impossible to accurately quantify the level of risk reduction, since this can only be measured from long-term 
epidemiological studies adjusting for past smoking. Considering that e-cigs are a recent development and that there is a significant delay between smoking initiation and smokingrelated disease, many years are needed for research to fully characterize the possible risk profile of e-cigs.

In that context, it may seem strange that there is so much controversy, strong debate, and differences in the regulatory approach to e-cigs. The main reason for this is the use of the precautionary principle. The key element of the precautionary principle is the justification for acting in the face of uncertain knowledge about risks. It mandates the issue of preventive measures before fully substantiating the risk and shifts the burden of proof from demonstrating the presence of risk to demonstrating the absence of risk. ${ }^{45}$ The 1992 Rio Declaration of the United Nations states that:

In order to protect the environment, the precautionary approach shall be widely applied by States according to their capabilities. Where there are threats of serious or irreversible damage, lack of full scientific certainty shall not be used as a reason for postponing cost-effective measures to prevent environmental degradation. ${ }^{46}$

The precautionary principle has been introduced in EU law since $2000 .^{47}$ Although it was initially applied to public health protection from environmental hazards, it has subsequently been used in other areas such as health, food policy, and consumer protection.

There has been a lot of criticism about the precautionary principle, especially when used as a basis for decisionmaking. ${ }^{48-51}$ However, even for those supporting the value and applicability of the precautionary principle in public health, it is difficult to currently justify the level of criticism for e-cigs and the need for restrictions up to the point of complete ban on e-cig products. As mentioned earlier, the application of this principle justifies taking precautionary measures before "full scientific certainty" has been achieved, but there must be at least some evidence of risk or harm.

\section{Evidence justifying the precautionary principle}

Much of the debate about e-cigs and the proposed or already implemented restrictions are based on the precautionary principle. There are four main arguments for applying the precautionary principle (Table 1): 1) the incentives and goals of the tobacco industry are to sustain nicotine addiction and profits; 2) e-cig use by nonsmokers and especially by youth may result in a new generation of nicotine addicts and may become a gateway to smoking; 3) e-cigs may prevent smoking cessation; and 4) e-cigs may be safer than smoking, but they are not absolutely safe, while dual use may result in added risk.

Table I Main arguments for applying the precautionary principle to e-cigarettes (e-cigs)

\begin{tabular}{|c|c|}
\hline Main arguments & Interpretation \\
\hline Incentives of tobacco industry & $\begin{array}{l}\text { Due to the past history of the tobacco industry, } \\
\text { there is fear that the incentives are to create a } \\
\text { new generation of nicotine addicts or to } \\
\text { maintain nicotine addiction to smokers }\end{array}$ \\
\hline $\begin{array}{l}\text { Adoption of e-cig use by youth } \\
\text { and/or nonsmokers - gateway } \\
\text { to smoking }\end{array}$ & $\begin{array}{l}\text { E-cigs renormalize smoking; they become } \\
\text { a new trend; they are marketed to } \\
\text { youth through the availability of flavors }\end{array}$ \\
\hline
\end{tabular}

\section{Evidence}

Fear legitimate due to past experience but

no substantiation that this is happening, strict

regulations will hand over the whole e-cig market

to the tobacco industry

There is significant experimentation but very low regular use, which is mostly confined to young smokers;

difficult to convince that a product competing with tobacco cigarettes will renormalize tobacco cigarette use; flavors are marketed to satisfy adult consumers demand; regulation on marketing and advertisement could deal with the risk of attracting nonsmoking adults or youth Cross-sectional studies cannot evaluate causation; e-cig experimentation cannot be reasonably associated with smoking cessation efforts and cannot successfully substitute smoking; studies have been mispresented and misinterpreted

Probably not harmless, but no proof of harm yet; nothing is absolutely safe in daily life; less harmful than smoking by a large margin; risks exaggerated by ignoring that it is the amount and not the presence of a chemical that defines toxicity; flavors safety when inhaled is unknown, but the best option is to use food-approved flavors; dual use may be beneficial if associated with significant smoking reduction, since e-cigs provide an alternative source of nicotine 


\section{Incentives of the tobacco industry}

Traditionally, tobacco harm reduction approaches has been viewed as a "Trojan horse" that serves the tobacco industry interests..$^{52}$ It has been mentioned that the only motive of the tobacco industry is to promote dual use of tobacco cigarettes and harm-reduction products so that the profit from cigarette sales is maintained. ${ }^{53}$ Many believe that e-cigs are just a new tool in the same strategy of the tobacco industry, sustaining dependence on nicotine. However, this ignores the fact that e-cigs were not developed by the tobacco industry. In fact, e-cigs were largely ignored by the tobacco industry until 2012, when the first acquisition of an independent e-cig company by Lorillard took place..$^{53}$ In the meantime, e-cig ever use increased fourfold from 2009 to 2010 and tenfold by $2011 .{ }^{22,54}$ In fact, e-cigs have been a consumer-initiated and consumer-driven product. Although the tobacco industry is justifiably approached with caution and suspicion due to past experience, there is no real evidence or substantiation that e-cigs are promoted by these companies as a way of protecting tobacco cigarette sales. Moreover, even if we accept that the only motive of the tobacco industry approach to e-cigs is for profit sustainability and not for genuine interest in public health, strict regulations will only promote the industry goals by handling the whole e-cig market to it since they have the financial and structural ability to comply with expensive regulations. This will additionally stifle innovation and competition, making e-cigs less effective as smoking substitutes. Finally, although it is true that e-cigs could probably sustain nicotine dependence, it should be emphasized that the goal of the public health is to reduce morbidity and mortality and not to enforce a specific behavior or to judge habits. Considering the minor impact of nicotine in smokingrelated disease and death, the public health should distance itself from an ideological war against nicotine use.

\section{E-cig use by nonsmokers and youth}

Another argument used by those supporting strict regulations and/or bans is related to e-cig use by youth and by neversmokers, and the potential of e-cigs to serve as a gateway to smoking. In many cases, the studies supporting such an argument suffer from methodological errors, while in other cases, there is mispresentation or misinterpretation of data. The US Centers for Disease Control and Prevention (CDC) has reported a continuous elevation in e-cig use among high school students from $1.5 \%$ in 2011 to $13.4 \%$ in $2014 .^{55}$ However, during the same time period, smoking prevalence has decreased from $15.8 \%$ to just $9.2 \% .{ }^{55}$ Although the data do not substantiate a causation link, they strongly question the gateway to smoking hypothesis because, in that case, an elevated smoking prevalence would have been expected. An analysis of the CDC data from 2011 to 2012 explored the association between e-cig use and smoking. ${ }^{56}$ The authors found that e-cig use was associated with higher odds of smoking and concluded that use of e-cigs does not discourage, and may encourage, conventional cigarette use. However, their conclusion was inappropriate considering that they were analyzing a cross-sectional survey and did not take into account population characteristics which play a crucial role when determining potential causation. This was evident when, using the same methodology in the analysis of the 2011 CDC data, it was found that pharmacological and nonpharmacological smoking-cessation interventions were also associated with higher odds of smoking as well as higher smoking frequency and higher tobacco cigarette consumption..$^{57}$ Obviously, it would have been unreasonable to support that smoking-cessation interventions probably encourage smoking; most likely, it is the heavier smokers who try several methods for smoking cessation, and those are the ones most likely to fail due to higher dependence. Moreover, the CDC surveys classify current e-cig use as use even on 1 of the past 30 days. A recent study showed that, among those reporting use in the past 30 days, the vast majority were infrequent users, especially for never-smokers $(89.5 \%){ }^{58}$ Therefore, CDC surveys exploring youth use suffer from an important methodological error, which does not allow the interpretation of e-cig use beyond trial related to curiosity. Studies using more appropriate questions in other countries, such as the UK, have found very low prevalence of regular use by youth or by never-smokers. ${ }^{59,60} \mathrm{~A}$ characteristic example of results mispresentation is a study of e-cig use in South Korean adolescents. ${ }^{61}$ A press release presented the study findings with a statement: "We are witnessing the beginning of a new phase of the nicotine epidemic and a new route to nicotine addiction for kids", referring to e-cigs. ${ }^{62}$ However, according to the study results, $18.3 \%$ of all participants were ever cigarette-only users, $8.0 \%$ were ever dual users (tobacco cigarette and e-cig), and only $1.4 \%$ were ever e-cig-only users. ${ }^{61}$ The authors clearly mentioned in the study: "It was rare for students no longer using cigarettes to be among current e-cigarette users". Obviously, the major problem in Korean adolescents is the high prevalence of tobacco cigarette use rather than e-cig use. Thus, although e-cig experimentation is increasing, there is no evidence of regular e-cig use by youth and never-smokers, while the gateway to smoking argument is largely hypothetical and not supported by current evidence. Another strong relevant argument is that flavors 
used in e-cigs are marketed to attract youth, and some authorities have tried to implement a ban on flavors availability (http://www.nydailynews.com/blogs/dailypolitics/bill-bansale-flavored-e-cigarettes-blog-entry-1.1965179). However, a survey of $>4,000$ e-cig users found that flavors are appealing to adult e-cig users, most of whom were ex-smokers, and that they played an important role in their effort to quit smoking and in preventing relapse to smoking. ${ }^{27}$

\section{E-cigs preventing smoking cessation}

The issue of e-cig use preventing smoking cessation has been extensively discussed based on the results of several studies. For example, Al-Delaimy et $\mathrm{al}^{63}$ surveyed 1,000 Californians at baseline and after 1 year. They evaluated whether e-cig use at baseline predicted quitting behavior at follow-up and found that reporting ever use of e-cigs reduced the odds of reducing cigarette consumption or quitting smoking. However, the study was not even designed to assess whether e-cigs promote or prevent smoking cessation and included a complex list of exclusion criteria which introduced strong bias. For example, assessing ever use at baseline might include people who had already tried e-cigs and failed before the follow-up period. Moreover, the comparison between smokers who had tried e-cigs at baseline and those who reported both at baseline and at follow-up was that they would never use e-cigs. It was inappropriate to define the control group using a variable determined at follow-up because, obviously, one of the reasons that some participants reported at follow-up that they would never use e-cigs is because they have quit smoking. Also, the authors excluded smokers who thought they would not or might not use e-cigs, but who ended up using these devices between baseline and follow-up. Again, some of them might have quit smoking by using e-cigs, but this group was not included in the analysis. The study made every effort to exclude those who might have succeeded in quitting smoking by using e-cigs between baseline and follow-up, and included only those who smoked and had ever used e-cigs at baseline. Another characteristic example of such misinterpretation was the study by Vickerman et al $^{64}$ from Alere Wellbeing smoking cessation services, in which they followed up smokers who had already failed to quit with e-cigs in the past and found that those who had tried e-cigs were less likely to quit. That was an expected finding, since smokers who had tried e-cigs had already failed to quit at baseline and most likely represented a group of smokers harder to quit. In fact, Alere Wellbeing clarified this issue in a press statement mentioning that:

The recently published article by Dr Katrina Vickerman and colleagues has been misinterpreted by many who have written about it. It was never intended to assess the effectiveness of the e-cig as a mechanism to quit. ${ }^{65}$

\section{E-cigs safer than smoking, but not absolutely safe}

It is commonly mentioned that, although e-cigs may be safer than smoking, they are not absolutely safe. There are many problems with this argument. It is a fact that some chemicals of concern have been found in e-cig liquids and aerosol. ${ }^{66-69}$ However, contaminants are present in almost every food product, water, and the environment. Thus, the term "absolute safety" is not accurate or applicable to modern daily life. We currently have no data on whether the minimal levels of toxins present in e-cigs could result in measurable adverse health effects, but probably there is some residual risk. Nevertheless, the main issue with e-cigs is to first define their safety in relation to smoking, and subsequently to find appropriate measures to make them as safe as possible. Some studies have overestimated the risk due to methodological errors, mostly abusing the e-cig devices in laboratory conditions, resulting in severe overheating and evaluating the aerosol content in unrealistic conditions. ${ }^{70-72}$ Another argument in the same context refers to dual use of tobacco and e-cigs. It has long been postulated that smoking reduction confers no risk reduction. ${ }^{73,74}$ However, those studies did not assess smoking reduction with the use of an alternative source of nicotine, thus it is highly likely that smoking reduction was accompanied by compensatory smoking which could maintain or even elevate the level of toxin exposure. ${ }^{75-77}$ Moreover, studies evaluating the effects of smoking reduction do not show consistent results, ${ }^{78,79}$ while other studies have shown an almost linear association between smoking consumption and disease incidence. ${ }^{80,81}$ Thus, the conclusion that dual use of tobacco cigarettes and e-cigs is not harm reduction ${ }^{82}$ is purely hypothetical and not supported by any evidence. In fact, dual use may have important health benefits if there is substantial reduction in cigarette consumption and if enough nicotine is obtained from e-cigs to prevent compensatory smoking. A preliminary study in a small group of asthmatics found that even dual use (with a significant reduction in consumption from 22 to five cigarettes per day) resulted in objective improvement of their disease condition. ${ }^{83}$ Moreover, dual use is an expected intermediate period before complete cessation. Finally, in the case of tobacco harm reduction, the public health impact is not only related to safety but also to acceptability and use by the consumers. For example, NRTs are very safe products, but because of the limited use and their limited efficacy in smoking reduction or cessation, they have a small public health impact. It is important to find 
the balance between acceptability and risk, overcoming the temptation to look only at safety.

In conclusion, the arguments used for applying the precautionary principle to implement severe restrictions or bans are mostly hypothetical and unsupported by evidence. Thus, although they definitely warrant monitoring and further research, they cannot be used to substantiate decisions on regulatory restrictions or bans. Moreover, applying strict regulations or sales bans will prevent the scientific community from exploring the unknowns and determining the true impact of e-cigs on public health.

\section{Regulatory proposals in the face of some uncertainty}

Between the many knowns and unknowns about e-cigs, there is one certainty: regulation is a necessity. In most cases, regulation is interpreted as restrictions. However, it should be regarded as setting proper rules that will ensure good quality products, removal of avoidable risks, and targeting the intended population (smokers), while avoiding initiation and long-term use by never-smokers. This is a very challenging process. It must take into account the following: how e-cigs are used in realistic settings, what are the potential benefits and risks from encouraging use, how will regulation comply with innovation and future development, and how to make the regulations financially sustainable to maintain a competitive advantage for e-cigs against tobacco cigarettes. Several options in regulating e-cigs are available (Table 2).

\section{Ban all e-cigs or nicotine-containing and flavored e-cigs}

One of the options is to ban e-cigs or selectively ban nicotine-containing liquids and/or flavors. This is based on the precautionary principle discussed earlier. A characteristic example of the problems related to such regulation is Canada, where electronic products that dispense nicotine by inhalation fall under the Food and Drugs Act of Health Canada and can only be marketed if being approved as new medications. As a result, Canadian smokers have to break the law if they want to have a reasonable chance of quitting smoking with the use of e-cigs.

A complete ban on e-cigs or nicotine-containing and flavored e-cigs would create significant ethical issues, ${ }^{84}$ related in some cases to unintended consequences. It would be a paradox to ban a less harmful form of nicotine intake (e-cigs), while allowing the sales of the most lethal form of nicotine intake (tobacco cigarettes). Nicotine seems to play an important role in the success of e-cigs to substitute smoking, especially during the period of e-cig use initiation, ${ }^{44,85}$ while flavors provide the necessary satisfaction not only to smokers but also to ex-smokers and now-established e-cig users, helping the former in their quitting attempts and the latter in preventing relapse. ${ }^{27}$ Banning nicotine or flavors would only make e-cigs less appealing to smokers. Even though there is currently no evidence that flavors attract never-smokers who subsequently become addicted to nicotine, an important ethical question is raised: should a product, which is probably beneficial for a part of the population (smokers), be restricted or banned (which could reduce or eliminate its efficacy as a smoking substitute) because some other parts of the population (nonsmokers) decide to voluntarily adopt its use and expose themselves to a new (even minor) risk? ${ }^{86}$ Finally, a decision to ban e-cigs would deprive scientists from the ability to verify or dismiss the health concerns forming the basis for applying the precautionary principle.

\section{Regulation as medicinal products}

Another option is to regulate e-cigs as medicinal products. This option was considered during the writing of the new EU Tobacco Product Directive, but this was dismissed by some

Table 2 Pros and cons of different regulatory approaches for e-cigarettes (e-cigs)

\begin{tabular}{|c|c|c|}
\hline Regulatory approach & Pros & Cons \\
\hline Ban on sales & Avoid use by nonintended population & Prevent smokers from using an alternative less harmful product \\
\hline $\begin{array}{l}\text { Ban on nicotine-containing } \\
\text { products }\end{array}$ & $\begin{array}{l}\text { Avoid nicotine intake by nonintended } \\
\text { population }\end{array}$ & $\begin{array}{l}\text { Does not address risk of using nonnicotine liquids; ban on } \\
\text { nicotine will make smoking cessation extremely difficult }\end{array}$ \\
\hline Medicinal regulation & Ensure maximum safety & $\begin{array}{l}\text { Extremely expensive; will make products unattractive; will hinder } \\
\text { innovation }\end{array}$ \\
\hline Tobacco regulation & $\begin{array}{l}\text { Ensure the application of restrictions } \\
\text { similar to tobacco products }\end{array}$ & $\begin{array}{l}\text { No need for applying restrictions similar to tobacco products; } \\
\text { false impression that e-cigs are of equal risk to tobacco products; } \\
\text { will discourage use by smokers }\end{array}$ \\
\hline Consumer regulation & E-cigs are used as consumer products & $\begin{array}{l}\text { Does not address specific issues relevant to e-cigs like nicotine } \\
\text { content; may create the impression that they could be used by } \\
\text { the whole population as a new habit }\end{array}$ \\
\hline
\end{tabular}


scientists $^{87}$ and was finally not retained in the final text. The main arguments for such regulation were to ensure consumer safety and accurate product labeling. Again, there are unintended consequences from following this path. Medicinal licensing requirement would hinder further development of e-cigs, because small improvements would require new licensing applications, dramatically extend the innovation timescale, and make the cost of innovation prohibitive. Consequently, the costs for e-cigs would increase, and tobacco cigarettes would remain a more attractive option for smokers because they are not subject to such regulation. Moreover, this would bar the route to small innovating companies, leaving the whole market to the tobacco and pharmaceutical companies, which have sufficient resources to handle these costs. It could also create a conflict of interest with their own products (cigarettes and medicines) and might undermine their willingness to further develop e-cigs. Finally, such a regulation would be contrary to the patterns of e-cig use by consumers, which is to substitute the experience perceived from smoking with a similar experience from a less harmful product; ${ }^{88}$ the huge variability of products and flavors is exactly serving the purpose of satisfying personal preference. ${ }^{27}$

\section{Regulation as tobacco products}

A third option is to regulate them as tobacco products. In fact, the FDA has the authority to regulate e-cigs in the USA because a tobacco product is legally defined as

... any product made or derived from tobacco that is intended for human consumption, including any component, part, or accessory of a tobacco product.

Thus, they consider e-cigs as tobacco products because nicotine is derived from tobacco. There are two pathways of obtaining approval for e-cigs according to the FDA proposals. The "substantial equivalence" pathway, which means proving that a new tobacco product (e-cig) entering the market is substantially equivalent to a "predicate product", meaning a product commercially marketed in the USA as of February 15,2007 . The second pathway is to apply for a premarket tobacco application. ${ }^{89}$ Both processes are cost prohibitive and would result in elimination of most of the e-cig products currently available on the market. Moreover, it makes no more sense to argue that nicotine-containing e-cigs are tobacco products than to argue that biodiesel is a vegetable product because it is derived from plants. ${ }^{88}$ Additionally, it would carry a misleading message to smokers that e-cigs are equally harmful as tobacco cigarettes. Of note, the EU has also regulated e-cigs through a tobacco directive, but there is a separate article about e-cigs with different requirements compared to tobacco cigarettes. Although there are many unnecessary and unexplained restrictions, such as a $20 \mathrm{mg} /$ $\mathrm{mL}$ limit in nicotine concentration of e-cig liquids, a $10 \mathrm{~mL}$ limit of refill bottle content, and a $2 \mathrm{~mL}$ limit in capacity of refillable atomizers, the regulation proposed by the EU is more moderate, feasible, and financially sustainable compared to the US FDA proposal.

\section{Regulation as consumer product}

In many countries, e-cigs are currently regulated as consumer products for which regulation already exists (consumer protection). One example is the requirement to make tamper-proof containers; this is not limited to medicines but also to consumer products such as bleach or other potentially harmful substances. Labeling rules apply for nicotine, depending on the concentration, based on classification, labeling, and packaging regulations. ${ }^{90}$ Although it is true that e-cigs are used as consumer products, such regulation may not be enough because it does not deal with issues specifically applied to e-cigs and could create the impression that e-cig use would be appropriate for everyone.

\section{Unique regulatory scheme}

A proper regulatory scheme should first of all ensure that smokers are honestly informed on the relative harmfulness of the different products at stake. This has not been achieved so far. The WHO (World Health Organization) Ottawa Charter, published in 1986, clearly stated that "People cannot achieve their fullest health potential unless they are able to take control of those things which determine their health" ${ }^{91}$ As stated in a WHO Europe report from $2006,{ }^{92}$ the concept of empowerment in public health should ensure

people's access to information on public health issues, their inclusion in decision-making, local organizational capacity to make demands on institutions and governing structures and accountability of institutions to the public.

So far, these needs have not been offered to the e-cig users. Considering all the aforementioned points, it is evident that e-cigs (as well as other novel reduced harm nicotine-containing products) have unique characteristics and a unique role to play in tobacco harm reduction. For this reason, a specific regulatory scheme is needed, separate from tobacco or medicinal products regulation. Regulation should implement specific quality criteria for products. Use of pharmaceutical grade ingredients where possible, as for propylene glycol, glycerol, and nicotine, should be mandatory and can be proven by providing appropriate 
documentation without the need for expensive testing. Rules for the exclusion of chemicals of reasonable concern should be implemented, together with appropriate testing for possible contaminants. For example, specific rules should apply for the presence of diacetyl and acetyl propionyl, chemicals that although safe when ingested have been linked with respiratory dysfunction when inhaled. ${ }^{68,93}$ Although safety is an important priority, it should be implemented in a way that will also ensure the acceptability and appeal of e-cigs for smokers; focusing solely on safety could result in making products that only few smokers would eventually use, minimizing the positive public health impact. Additionally, manufacturing standards derived from the food industry should be implemented, adjusted for specific conditions related to e-cigs, such as handling of nicotine solutions, contamination of non-nicotine products with nicotine, etc. Labeling should be specified, with warnings about exposure to skin or through ingestion and discouragement of use by nonsmokers, related to the presence of nicotine. Finally, advertising and marketing should not be banned, but appropriately regulated in order to promote use by the intended population while avoiding use by never-smokers.

\section{Conclusion}

E-cigs are a disruptive technology, with a large potential to change the history of the tobacco epidemic. Being a new product, there are several unknowns which need further research to be fully examined. However, currently available evidence is certainly showing that application of the precautionary principle to severely restrict or ban e-cig accessibility and sales is inappropriate, resulting in many unintended adverse consequences without any established benefit. The approach to regulation should be proportionate, realistic, and with the purpose of maintaining a competitive advantage for e-cigs versus tobacco cigarettes. Finding the appropriate balance between safety and acceptability of use by smokers will be important in achieving the maximum public health benefit.

\section{Acknowledgment}

No funding was provided for this study.

\section{Disclosure}

A small minority of KEF's studies were performed using unrestricted funds provided to the institution (Onassis Cardiac Surgery Center) by e-cigarette companies. JLH has received speaker honoraria and consultancy fees from Johnson \& Johnson, Novartis, Pfizer, and Pierre Fabre. The authors report no other conflicts of interest in this work.

\section{References}

1. American Psychiatric Association. Diagnostic and Statistical Manual of Mental Disorders. 4th ed. Washington, DC: American Psychiatric Association; 1994.

2. World Health Organization. International Classification of Diseases, 10th Revision (ICD-10). Geneva, Switzerland: World Health Organization; 1992.

3. George TP, Weinberger AH. Monoamine oxidase inhibition for tobacco pharmacotherapy. Clin Pharmacol Ther. 2008;83(4):619-621.

4. Berlin I, Saïd S, Spreux-Varoquaux O, Olivares R, Launay JM, Puech AJ. Monoamine oxidase A and B activities in heavy smokers. Biol Psychiatr. 1995;38:756-761.

5. Benowitz NL. Nicotine addiction. $N$ Engl J Med. 2010;362(24): 2295-2303.

6. World Health Organization. WHO Global Report: Mortality Attributable to Tobacco. Geneva, Switzerland: WHO; 2012. Available from: http://www.who.int/tobacco/publications/surveillance/rep_mortality_ attributable/en/index.html. Accessed July 20, 2015.

7. Jha P. Avoidable global cancer deaths and total deaths from smoking. Nat Rev Cancer. 2009;9(9):655-664.

8. Doll R, Peto R, Boreham J, Sutherland I. Mortality in relation to smoking: 50 years' observation on male British doctors. BMJ. 2004; 328(7455):1519.

9. Pirie K, Peto R, Reeves GK, Green J, Beral V; Million Women Study Collaborators. The 21st century hazards of smoking and benefits of stopping: a prospective study of one million women in the UK. Lancet. 2013;381(9861):133-141.

10. Le Houezec J. Role of nicotine pharmacokinetics in nicotine addiction and nicotine replacement therapy: a review. Int J Tuberc Lung Dis. 2003;7:811-819.

11. Royal College of Physicians. Harm Reduction in Nicotine Addiction. London, UK: Royal College of Physicians; 2007.

12. Cummings KM, Hyland A, Giovino GA, Hastrup JL, Bauer JE, Bansal MA. Are smokers adequately informed about the health risks of smoking and medicinal nicotine? Nicotine Tob Res. 2004;6(Suppl 3):S333-S340.

13. Siahpush M, McNeill A, Borland R, Fong G. Socioeconomic variations in nicotine dependence, self-efficacy and intention to quit across four countries: findings from the International Tobacco Control Policy Evaluation Survey. Tob Control. 2006;15(Suppl III):iii71-iii75.

14. Le Houezec J, McNeill A, Britton J. Tobacco, nicotine and harm reduction. Drug Alcohol Rev. 2011;30(2):119-123.

15. Royal College of Physicians. Ending Tobacco Smoking in Britain. Radical Strategies for Prevention and Harm Reduction in Nicotine Addiction. London, UK: Royal College of Physicians; 2008. Available from: http://www.rcplondon.ac.uk/publications/ending-tobaccosmoking-britain. Accessed July 20, 2015.

16. Benowitz NL. Smokeless tobacco as a nicotine delivery device: harm or harm reduction? Clin Pharmacol Ther. 2011;90(4):491-493.

17. Murray RP, Bailey WC, Daniels K, et al. Safety of nicotine polacrilex gum used by 3,094 participants in the Lung Health Study. Lung Health Study Research Group. Chest. 1996;109(2):438-445.

18. Benowitz NL, Gourlay SG. Cardiovascular toxicity of nicotine: implications for nicotine replacement therapy. $\mathrm{J} \mathrm{Am} \mathrm{Coll} \mathrm{Cardiol.}$ 1997;29(7):1422-1431.

19. Medicines and Healthcare Products Regulatory Agency. Nicotine Replacement Therapy (NRT) and harm reduction. London, UK: Medicines and Healthcare Products Regulatory Agency; 2010. Available from: https://www.gov.uk/drug-safety-update/nicotine-replacementtherapy-and-harm-reduction. Accessed January 20, 2014.

20. National Institute for Health and Care Excellence. Tobacco-HarmReduction Approaches to Smoking: Guidance. London, UK: National Institute for Health and Care Excellence; 2013. Available from: http:// www.nice.org.uk/guidance/PH45. Accessed January 20, 2014.

21. Gray N, Boyle P. The future of the nicotine-addiction market. Lancet. 2003;362(9387):845-846.

22. King BA, Alam S, Promoff G, Arrazola R, Dube SR. Awareness and ever-use of electronic cigarettes among US. adults, 2010-2011. Nicotine Tob Res. 2013;15(9):1623-1627. 
23. Dockrell M, Morrison R, Bauld L, McNeill A. E-cigarettes: prevalence and attitudes in Great Britain. Nicotine Tob Res. 2013;15(10):1737-1744.

24. Adkison SE, O'Connor RJ, Bansal-Travers M, et al. Electronic nicotine delivery systems: international tobacco control four-country survey. Am J Prev Med. 2013;44(3):207-215.

25. European Commission. Eurobarometer 385. Attitudes of Europeans towards Tobacco. Brussels, Luxembourg: European Commission; 2012. Available from: http://ec.europa.eu/public_opinion/archives/ebs/ ebs_385_en.pdf. Accessed July 13, 2015.

26. Zhu SH, Sun JY, Bonnevie E, et al. Four hundred and sixty brands of e-cigarettes and counting: implications for product regulation. $T o b$ Control. 2014;23(Suppl 3):iii3-iii9.

27. Farsalinos KE, Romagna G, Tsiapras D, Kyrzopoulos S, Spyrou A, Voudris V. Impact of flavour variability on electronic cigarette use experience: an internet survey. Int J Environ Res Public Health. 2013; 10(12):7272-7282.

28. Buchhalter AR, Acosta MC, Evans SE, Breland AB, Eissenberg T. Tobacco abstinence symptom suppression: the role played by the smoking-related stimuli that are delivered by denicotinized cigarettes. Addiction. 2005;100(4):550-559.

29. Vansickel AR, Cobb CO, Weaver MF, Eissenberg TE. A clinical laboratory model for evaluating the acute effects of electronic "cigarettes": nicotine delivery profile and cardiovascular and subjective effects. Cancer Epidemiol Biomarkers Prev. 2010;19(8):1945-1953.

30. Bullen C, McRobbie H, Thornley S, Glover M, Lin R, Laugesen M. Effect of an electronic nicotine delivery device (e cigarette) on desire to smoke and withdrawal, user preferences and nicotine delivery: randomised cross-over trial. Tob Control. 2010;19(2):98-103.

31. Farsalinos KE, Spyrou A, Tsimopoulou K, Stefopoulos C, Romagna G, Voudris V. Nicotine absorption from electronic cigarette use: comparison between first and new-generation devices. Sci Rep. 2014;4:4133.

32. Farsalinos KE, Spyrou A, Stefopoulos C, et al. Nicotine absorption from electronic cigarette use: comparison between experienced consumers (vapers) and naïve users (smokers). Sci Rep. 2015;5:11269.

33. Fairchild AL, Bayer R, Colgrove J. The renormalization of smoking? E-cigarettes and the tobacco "endgame". N Engl J Med. 2014;370(4): 293-295.

34. Jollye L. E-cigarettes in the UK: a more inclusive debate is needed. Lancet. 2014;384(9954):1576.

35. Harris JK, Moreland-Russell S, Choucair B, Mansour R, Staub M, Simmons K. Tweeting for and against public health policy: response to the Chicago Department of Public Health's electronic cigarette Twitter campaign. J Med Internet Res. 2014;16(10):e238.

36. McKee M, Chapman S, Daube M, Glantz S. The debate on electronic cigarettes. Lancet. 2014;384(9960):2107.

37. Etter JF. E-cigarettes: methodological and ideological issues and research priorities. BMC Med. 2015;13:32.

38. McNeill A, Etter JF, Farsalinos K, Hajek P, le Houezec J, McRobbie H. A critique of a World Health Organization-commissioned report and associated paper on electronic cigarettes. Addiction. 2014;109(12): $2128-2134$

39. Farsalinos KE, Polosa R. Safety evaluation and risk assessment of electronic cigarettes as tobacco cigarette substitutes: a systematic review. Ther Adv Drug Saf. 2014;5(2):67-86.

40. Grana R, Benowitz N, Glantz SA. E-cigarettes: a scientific review. Circulation. 2014;129(19):1972-1986.

41. Hajek P, Etter JF, Benowitz N, Eissenberg T, McRobbie H. Electronic cigarettes: review of use, content, safety, effects on smokers and potential for harm and benefit. Addiction. 2014;109(11):1801-1810.

42. Tremblay MC, Pluye P, Gore G, Granikov V, Filion KB, Eisenberg MJ. Regulation profiles of e-cigarettes in the United States: a critical review with qualitative synthesis. BMC Med. 2015;13(1):130.

43. Gourdet CK, Chriqui JF, Chaloupka FJ. A baseline understanding of state laws governing e-cigarettes. Tob Control. 2014;23(Suppl 3):iii37-iii40.

44. Farsalinos KE, Romagna G, Tsiapras D, Kyrzopoulos S, Voudris V. Characteristics, perceived side effects and benefits of electronic cigarette use: a worldwide survey of more than 19,000 consumers. Int J Environ Res Public Health. 2014;11(4):4356-4373.
45. Grandjean P, Bailar JC, Gee D, et al. Implications of the Precautionary Principle in research and policy-making. Am J Ind Med. 2004;45(4): 382-385.

46. Rio Declaration on Environment and Development. Stockholm, Sweden: United Nations; 1992. Publication E.73.II.A.14. Available from: http://www.un.org/documents/ga/conf151/aconf15126-1annex1. htm. Accessed July 23, 2015.

47. European Commission. Communication from the Commission on the Precautionary Principle. COM(2000) 1. Brussels, 2000. Brussels, Luxembourg: European Commission. Available from: http://ec.europa. eu/dgs/health_consumer/library/pub/pub07_en.pdf. Accessed July 22, 2015.

48. Peterson M. The precautionary principle should not be used as a basis for decision-making. Talking point on the precautionary principle. EMBO Rep. 2007;8(4):305-308.

49. Goldstein BD, Carruth RS. Implications of the Precautionary Principle: is it a threat to science? Int J Occup Med Environ Health. 2004;17(1): 153-161.

50. ter Meulen RH. The ethical basis of the precautionary principle in health care decision making. Toxicol Appl Pharmacol. 2005;207(2 Suppl): 663-667.

51. Peterson M. The precautionary principle is incoherent. Risk Anal. 2006;26(3):595-601.

52. Bell K, Stimson GV. Nicotine: science, regulation and policy. Int $J$ Drug Policy. 2015;26(6):533-535.

53. Esterl M. Got a light - er charger? Big tobacco's latest buzz. Wall Street Journal. 2012. Available from: http://www.wsj.com/articles/SB100014 24052702304723304577365723851497152. Accessed July 23, 2015.

54. Regan AK, Promoff G, Dube SR, Arrazola R. Electronic nicotine delivery systems: adult use and awareness of the 'e-cigarette' in the USA. Tob Control. 2013;22(1):19-23.

55. Arrazola RA, Singh T, Corey CG, et al. Centers for Disease Control and Prevention (CDC). Tobacco use among middle and high school students - United States, 2011-2014. MMWR Morb Mortal Wkly Rep. 2015;64(14):381-385.

56. Dutra LM, Glantz SA. Electronic cigarettes and conventional cigarette use among US adolescents: a cross-sectional study. JAMA Pediatr. 2014;168(7):610-617.

57. Farsalinos KE, Polosa R. Youth tobacco use and electronic cigarettes. JAMA Pediatr. 2014;168(8):775.

58. Amato MS, Boyle RG, Levy D. How to define e-cigarette prevalence? Finding clues in the use frequency distribution. Tob Control. Epub June 17, 2015.

59. Action on Smoking and Health UK. Use of Electronic Cigarettes (Vapourisers) among Adults in Great Britain. London, UK: Action on Smoking and Health UK; 2015. Available from: http://www.ash.org. uk/files/documents/ASH_891.pdf. Accessed July 23, 2015.

60. Moore G, Hewitt G, Evans J, et al. Electronic-cigarette use among young people in Wales: evidence from two cross-sectional surveys. BMJ Open. 2015;5(4):e007072.

61. Lee S, Grana RA, Glantz SA. Electronic cigarette use among Korean adolescents: a cross-sectional study of market penetration, dual use, and relationship to quit attempts and former smoking. $J$ Adolesc Health. 2014;54(6):684-690.

62. University of California San Francisco. Electronic Cigarettes: New Route to Smoking Addiction for Adolescents. San Francisco, CA: University of California. Available from: http://www.ucsf.edu/ news/2013/11/110416/electronic-cigarettes-new-route-smokingaddiction-adolescents. Accessed July 23, 2015.

63. Al-Delaimy WK, Myers MG, Leas EC, Strong DR, Hofstetter CR. E-cigarette use in the past and quitting behavior in the future: a population-based study. Am J Public Health. 2015;105(6):1213-1219.

64. Vickerman KA, Carpenter KM, Altman T, Nash CM, Zbikowski SM. Use of electronic cigarettes among state tobacco cessation quitline callers. Nicotine Tob Res. 2013;15(10):1787-1791.

65. Alere blog. E-Cigs: Are They A Problem Or A Solution? Available from: http://blog.alerewellbeing.com/bid/288222/E-Cigs-Are-TheyA-Problem-Or-A-Solution. Accessed July 23, 2015. 
66. Varlet V, Farsalinos K, Augsburger M, Thomas A, Etter JF. Toxicity assessment of refill liquids for electronic cigarettes. Int J Environ Res Public Health. 2015;12(5):4796-4815.

67. Farsalinos KE, Voudris V, Poulas K. Are metals emitted from electronic cigarettes a reason for health concern? A risk-assessment analysis of currently available literature. Int $J$ Environ Res Public Health. 2015;12(5):5215-5232.

68. Farsalinos KE, Kistler KA, Gillman G, Voudris V. Evaluation of electronic cigarette liquids and aerosol for the presence of selected inhalation toxins. Nicotine Tob Res. 2015;17(2):168-174.

69. Goniewicz ML, Knysak J, Gawron M, et al. Levels of selected carcinogens and toxicants in vapour from electronic cigarettes. Tob Control. 2014;23(2):133-139.

70. Jensen RP, Luo W, Pankow JF, Strongin RM, Peyton DH. Hidden formaldehyde in e-cigarette aerosols. N Engl J Med. 2015;372(4):392-394.

71. Nitzkin JL, Farsalinos K, Siegel M. More on hidden formaldehyde in e-cigarette aerosols. N Engl J Med. 2015;372(16):1575.

72. Farsalinos KE, Voudris V, Poulas K. E-cigarettes generate high levels of aldehydes only in 'dry puff' conditions. Addiction. 2015;110(8): 1352-1356.

73. Tverdal A, Bjartveit $\mathrm{K}$. Health consequences of reduced daily cigarette consumption. Tob Control. 2006;15(6):472-480.

74. Hart C, Gruer L, Bauld L. Does smoking reduction in midlife reduce mortality risk? Results of 2 long-term prospective cohort studies of men and women in Scotland. Am J Epidemiol. 2013;178(5):770-779.

75. Djordjevic MV, Fan J, Ferguson S, Hoffmann D. Self-regulation of smoking intensity. Smoke yields of the low-nicotine, low-'tar' cigarettes. Carcinogenesis. 1995;16(9):2015-2021.

76. Djordjevic MV, Hoffmann D, Hoffmann I. Nicotine regulates smoking patterns. Prev Med. 1997;26(4):435-440.

77. Scherer G. Smoking behaviour and compensation: a review of the literature. Psychopharmacology (Berl). 1999;145(1):1-20.

78. Lee PN. The effect of reducing the number of cigarettes smoked on risk of lung cancer, COPD, cardiovascular disease and FEV(1) - a review. Regul Toxicol Pharmacol. 2013;67(3):372-381.

79. Godtfredsen NS, Prescott E, Osler M. Effect of smoking reduction on lung cancer risk. JAMA. 2005;294(12):1505-1510.

80. Teo KK, Ounpuu S, Hawken S, et al; INTERHEART Study Investigators. Tobacco use and risk of myocardial infarction in 52 countries in the INTERHEART study: a case-control study. Lancet. 2006;368(9536):647-658.

81. Yamaguchi N, Mochizuki-Kobayashi Y, Utsunomiya O. Quantitative relationship between cumulative cigarette consumption and lung cancer mortality in Japan. Int J Epidemiol. 2000;29(6):963-968.

82. Chapman S, Daube M. Ethical imperatives assuming ENDS effectiveness and safety are fragile. Addiction. 2015;110(7):1068-1069.
83. Polosa R, Morjaria J, Caponnetto P, et al. Effect of smoking abstinence and reduction in asthmatic smokers switching to electronic cigarettes: evidence for harm reversal. Int J Environ Res Public Health. 2014; 11(5):4965-4977.

84. Hall W, Gartner C, Forlini C. Ethical issues raised by a ban on the sale of electronic nicotine devices. Addiction. 2015;110(7):1061-1067.

85. Farsalinos KE, Romagna G, Tsiapras D, Kyrzopoulos S, Voudris V. Evaluating nicotine levels selection and patterns of electronic cigarette use in a group of "vapers" who had achieved complete substitution of smoking. Subst Abuse. 2013;7:139-146.

86. Farsalinos KE, Voudris V, Le Houezec J. Risks of attempting to regulate nicotine flux in electronic cigarettes. Nicotine Tob Res. 2015;17(2): 163-164.

87. Hajek P, Foulds J, Le Houezec J, Sweanor D, Yach D. Should e-cigarettes be regulated as a medicinal device? Lancet Respir Med. 2013;1(6):429-431.

88. Farsalinos KE, Stimson GV. Is there any legal and scientific basis for classifying electronic cigarettes as medications? Int $J$ Drug Policy. 2014;25(3):340-345.

89. Federal Register. Proposed Rule by the Food and Drug Administration. Deeming Tobacco Products to be Subject to the Federal Food, Drug, and Cosmetic Act, as Amended by the Family Smoking Prevention and Tobacco Control Act; Regulations on the Sale and Distribution of Tobacco Products and Required Warning Statements for Tobacco Products. Washington, DC: Federal Register; 2014. Available from: https://www.federalregister.gov/articles/2014/04/25/2014-09491/ deeming-tobacco-products-to-be-subject-to-the-federal-food-drug-andcosmetic-act-as-amended-by-the. Accessed July 23, 2015

90. Official Journal of the European Union. Regulation (EC) No 1272/2008 of the European Parliament and of the Council of 16 December 2008 on classification, labelling and packaging of substances and mixtures, amending and repealing Directives 67/548/EEC and 1999/45/EC, and amending Regulation (EC) No 1907/2006. December 2008. Available from: http://eur-lex.europa.eu/LexUriServ/LexUriServ.do?uri=OJ:L:2 008:353:0001:1355:EN:PDF. Accessed July 23, 2015.

91. World Health Organization. Ottawa Charter for Health Promotion, 1986. Geneva, Switzerland: WHO. Available from: http://www.euro. who.int/_data/assets/pdf_file/0004/129532/Ottawa_Charter.pdf. Accessed July 28, 2015.

92. WHO Europe. What is the Evidence on Effectiveness of Empowerment to Improve Health? København, Denmark: WHO Europe. Available from: http://www.euro.who.int/_data/assets/pdf_file/0010/74656/ E88086.pdf. Accessed July 28, 2015.

93. Kanwal R, Kullman G, Piacitelli C, et al. Evaluation of flavorings-related lung disease risk at six microwave popcorn plants. J Occup Environ Med. 2006;48(2):149-157.
Risk Management and Healthcare Policy

\section{Publish your work in this journal}

Risk Management and Healthcare Policy is an international, peerreviewed, open access journal focusing on all aspects of public health, policy, and preventative measures to promote good health and improve morbidity and mortality in the population. The journal welcomes submitted papers covering original research, basic science, clinical \& epidemio-

\section{Dovepress}

logical studies, reviews and evaluations, guidelines, expert opinion and commentary, case reports and extended reports. The manuscript management system is completely online and includes a very quick and fair peerreview system, which is all easy to use. Visit http://www.dovepress.com/ testimonials.php to read real quotes from published authors. 